\section{Fronteiras da Terapia Cognitiva}

Salkovskis PM, editor. São Paulo: Casa do Psicólogo; 2004. 460 p. ISBN 85-7396-380-8

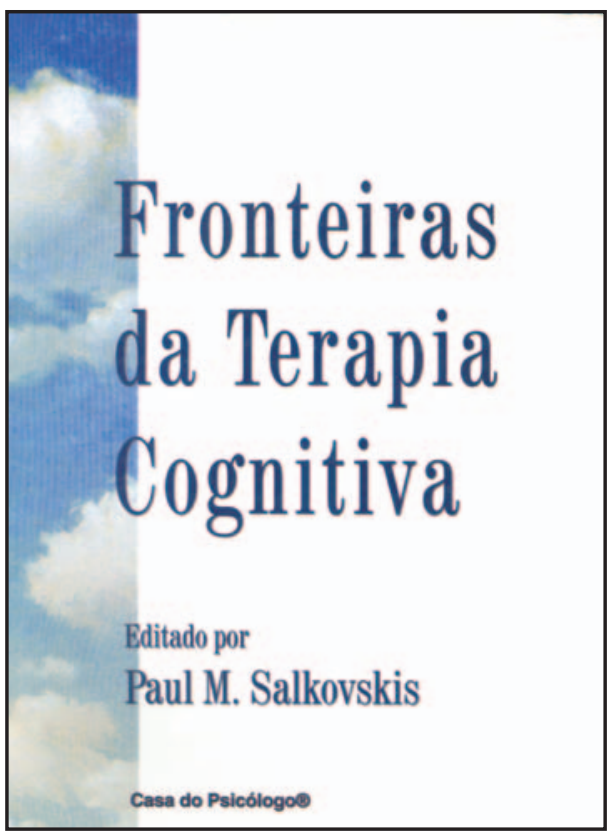

Paul Salkovskis, organizador da obra Fronteiras da Terapia Cognitiva, novamente se mostra um pesquisador, docente e terapeuta de primeira linha. A presente obra demonstra o expressivo impacto do trabalho de Aaron Beck, criador da abordagem cognitiva, para a formulação conceitual, pesquisa e prática clínica de transtornos psicológicos e psiquiátricos.

Vários profissionais de renome ofereceram seus conhecimentos especializados, discutindo em profundidade questões conceituais, metodológicas e técnicas da terapia cognitiva, demonstrando, em panorâmica, o amplo alcance do pensamento de Beck para a prática terapêutica. Jovens pesquisadores e terapeutas em formação certamente se beneficiarão com esta leitura.

Ao mesmo tempo, Beck, nesta obra, foi convidado a apresentar e discutir, de maneira sistemática, as mais recentes transformações conceituais da abordagem que criou: o leitor entrará em contato com a noção de "modos" e o conceito de "cargas", caracterizando a abordagem cognitiva como uma teoria em andamento. Beck didaticamente reviu os conceitos originais e propôs os acréscimos que julgou necessários, em compasso com as contingências reguladoras das formulações teóricas. Para ele, os novos conceitos auxiliam na compreensão de fenômenos complexos.

Em termos gerais, poucos autores dos demais capítulos teceram seus comentários a partir das reformulações conceituais que Beck julgou essenciais. Teasdale foi uma das exceções: no Capítulo 2, assimilou as transformações de Beck, formulou o conceito de Subsistemas Cognitivos Integrativos (SCl) e estabeleceu um paralelo com o conceito de "modos". Parece cedo demais para se proceder à avaliação do impacto dos novos conceitos sobre a prática dos outros pesquisadores e clínicos na abordagem cognitiva e talvez haja um intervalo de tempo entre a elaboração de um conceito e sua disseminação entre a comunidade. Uma explicação alternativa é de que a teoria não precisaria destes acréscimos para responder às demandas clínicas, sob a ótica de seus praticantes.

No Capítulo 4, Clark e Steer avaliam, com rigor e didatismo, as pesquisas disponíveis acerca de validação dos conceitos básicos; evidências favoráveis ao cognitivismo recebem igual atenção que dúvidas e aspectos a esclarecer. Por outro lado, o capitulo de autores respeitados como Weissenburger e Rush decepciona o leitor: discutem a interface mente e cérebro (ou biologia e cognições) com base em pesquisas realizadas apenas até 1993. O intervalo de tempo entre os dados por eles discutidos e a publicação deste capítulo prejudicou sensivelmente a análise realizada.

Há capítulos de extremo valor para a formação de terapeutas, independentemente de serem cognitivos, comportamentais ou de outra abordagem: neles, são detalhadamente apresentadas intervenções clínicas, ensinam-se habilidades do terapeuta (empatia, por exemplo) e diversos problemas clínicos recebem formulações bem estruturadas (tanto em termos de suas variáveis de controle, como das condutas terapêuticas). Nesta categoria, destacam-se (além das contribuições de Salkovskis) os trabalhos de Burns e Auerbach, o capítulo de Padesky, Clark e David, o texto de Chambless e Hope, o de Vitousek, além do capítulo de autoria de Liese e Franz.

Uma questão epistemológica que permaneceu praticamente sem discussão, mas cujos sinais transparecem em vários capítulos, é o estabelecimento de fronteiras e a avaliação da compatibilidade entre o cognitivismo e as abordagens freudiana (ocasionalmente mencionada por outrora estudiosos desta forma de entender o homem) e a comportamental (há quem se apresente como cognitivo, enquanto outros autores não hesitam em escrever seus capítulos com base no que denominam terapia comportamental-cognitiva). Não há respostas prontas e consensuais para esta discussão complexa, de natureza filosófica, conceitual, metodológica e tecnológica. Apenas destaco que, nesta obra de terapia cognitiva, há certamente influência de outras correntes de pensamento, o que pode, ou não, ter ocorrido de maneira consciente e planejada.

Por fim, três pequenos inconvenientes da edição brasileira: 0 capítulo 18 (de Sbrocco e Barlow) foi prejudicado por receber uma tradução de qualidade bastante inferior à dos demais capítulos (a página 382 nos oferece uma amostra do problema), com tradução linear das construções típicas da língua inglesa. Em outro capítulo, dois cochilos de revisão: "sesejos" (p. 412) e "ourecaída" (p. 413). Por fim, julgo inaceitável que o manuseio cuidadoso da obra, pela autora da resenha, já tenha produzido folhas soltas da lombada...

Salkovskis merece a gratidão de toda a comunidade pelo seu senso de justiça e generosidade para com Beck, pela riqueza dos próprios escritos e pelos acertos na escolha dos temas e autores dos capítulos. Beck e a terapia cognitiva foram realmente apresentados com uma vitalidade que cativa o leitor, seja este um principiante ou experiente profissional.

\section{Regina Christina Wielenska}

Doutora em Psicologia Experimental, Instituto de Psicologia, Universidade de São Paulo (USP), São Paulo (SP), Brasil 